МЕТАБОЛИЧЕСКАЯ ЭНДОТОКСИНЕМИЯ: ВОЗМОЖНЫЕ ПРИЧИНЫ И ПОСЛЕДСТВИЯ

\author{
(с) В.А. Белоглазов, И.А. Яцков*, Е.Д. Кумельский, В.В. Половинкина
}

Крымский федеральный университет имени В.И. Вернадского, Медицинская академия имени С.И. Георгиевского, Симферополь, Россия

В данной обзорной статье представлены сведения из литературных источников, которые дают представление о связи метаболических нарушений, возникающих на фоне ожирения, с эндотоксинемией, а также влиянии этих состояний на поддержание низкоинтенсивного воспаления в организме. Приведено описание гормональной и иммунной перестройки белой жировой ткани, основных путей поступления и метаболизма эндотоксина. Особое внимание уделено механизмам взаимного влияния ожирения и эндотоксинемии. Описанные М.Ю. Яковлевым в 1988 г. «эндотоксиновая агрессия» и P.D. Cani и соавт. в 2007 г. «метаболическая эндотоксинемия», на наш взгляд, являются одними из важнейших триггеров развития и прогрессирования целого спектра острых и хронических заболеваний. Исходя из данных последних лет, жировая ткань представляет собой активный эндокринный орган, способный оказывать влияние как на обменные процессы, так и на состояние врожденных и приобретенных механизмов иммунной защиты. В настоящее время доказано, что высококалорийные диеты приводят к увеличению не только избыточной массы тела, но и уровня циркулирующего в крови эндотоксина. Углубленное изучение способности ожирения и эндотоксинемии потенцировать взаимное провоспалительное действие может помочь как в понимании патогенеза основных сердечно-сосудистых, аутоиммунных, аллергических и инфекционных (в том числе вирусных) заболеваний, так и в разработке методов нефармакологической и медикаментозной коррекции данных состояний.

КЛЮЧЕВЫЕ СЛОВА: метаболическая эндотоксинемия; ожирение; эндотоксин; ЛПС.

\title{
METABOLIC ENDOTOXEMIA: POSSIBLE CAUSES AND CONSEQUENCES
}

\author{
(c) Vladimir A. Beloglazov, Igor A. Yatskov*, Evgeny D. Kumelsky, Valeria V. Polovinkina
}

V.I. Vernadsky Crimean Federal University, S.I. Georgievsky Medical Academy, Simferopol, Russia

This review article presents data from the literature, which provide an idea of the relationship between metabolic disorders occurring against the background of obesity and endotoxinemia, as well as the effect of these conditions on the maintenance of low-grade inflammation in the body. A description of the hormonal and immune restructuring of white adipose tissue, the main routes of entry and metabolism of endotoxin is given. Particular attention is paid to the mechanisms of the mutual influence of obesity and endotoxinemia. Described by Yakovlev M.Yu. in 1988 «endotoxin aggression» and Cani P.D. et al. in 2007, «metabolic endotoxinemia», in our opinion, is one of the most important triggers for the development and progression of a whole spectrum of acute and chronic diseases. Based on the data of recent years, adipose tissue is an active endocrine organ capable of influencing both metabolic processes and the state of innate and acquired immune defense mechanisms. It has now been proven that high-calorie diets lead not only to an increase in overweight, but also to an increase in the level of endotoxin circulating in the blood. An in-depth study of the ability of obesity and endotoxinemia to potentiate the mutual pro-inflammatory effect can help both in understanding the pathogenesis of the main cardiovascular, autoimmune, allergic and infectious (including viral) diseases, and in the development of methods for non-pharmacological and drug correction of these conditions.

KEYWORDS: metabolic endotoxemia; obesity; endotoxin; LPS.

Ожирение является серьезным фактором, отягощающим многие острые и хронические патологические процессы, происходящие в организме. Приблизительно 65\% взрослого населения США и более 100 млн человек во всем мире имеют избыточный вес или ожирение [1, 2]. Данные последних лет свидетельствуют о том, что жировая ткань является не только депо энергетического материала, но и достаточно сложно устроенным иммунным и эндокринным органом [3]. Ожирение характеризуется низкоинтенсивным воспалением, связанным с повышением уровня системных и местных провоспалительных цитокинов [4]. Подтверждена роль иммунного дисба- ланса при ожирении в развитии диабета II типа (СД2), метаболического синдрома и сердечно-сосудистых заболеваний $[5,6]$. Также интерес представляет взаимосвязь параметров метаболических нарушений и эндотоксинемии, что, по данным отечественных и зарубежных исследований, может потенцировать многочисленные нарушения эффекторных механизмов поддержания гомеостаза [7-10].

Путем анализа баз данных MEDLINE (PubMed) по данным на май 2021 г. был проведен поиск по ключевым словам «metabolic endotoxemia», «endotoxin and obesity» и «LPS and obesity», а также поиск в библиотеке eLibrary 


\begin{tabular}{lcc}
\hline \multicolumn{1}{c}{ Адипокины и цитокины } & БЖТ при ожирении & БЖТ у худых \\
\hline Адипонектин & $\downarrow$ & $\uparrow$ \\
\hline Адипсин & $\downarrow$ & $\uparrow$ \\
\hline Оментин & $\downarrow$ & $\uparrow$ \\
\hline IL-10, IL-4 & $\downarrow$ & $\uparrow$ \\
\hline Лептин & $\uparrow$ & $\downarrow$ \\
\hline Резистин & $\uparrow$ & $\downarrow$ \\
\hline Висфатин & $\uparrow$ & $\downarrow$ \\
\hline Хемерин & $\uparrow$ & $\downarrow$ \\
\hline TNF-a, IL-6, MCP-1 & $\uparrow$ & $\downarrow$ \\
\hline
\end{tabular}

Рисунок 1. Изменение баланса провоспалительных и противовоспалительных адипокинов и цитокинов при ожирении.

по ключевым словам «метаболическая эндотоксинемия» и «ожирение и эндотоксинемия». Большинство научных статей, представленных в данном литературном обзоре, опубликовано за последние 5 лет.

\section{ЖИРОВАЯ ТКАНЬ В НОРМЕ И ПРИ ОЖИРЕНИИ}

Для понимания роли жировой ткани в регуляции иммунных процессов необходимо знать основные изменения, происходящие в белой жировой ткани (БЖТ) у худых людей и лиц с ожирением. БЖТ депонируется под кожей, в брюшной полости и в парависцеральной клетчатке большинства органов. У мужчин 10-20\% жировой ткани расположено висцерально, тогда как у женщин - только 5-8\% [11]. Между подкожной и висцеральной БЖТ существует множество физиологических различий; адипоциты висцеральной БЖТ более инсулинорезистентны, метаболически активны и обладают большей липолитической активностью [3]. Кроме того, накопление висцерального жира связано с повышенным риском развития сахарного диабета 2 типа (СД2) и метаболического синдрома [12-14]. Хотя БЖТ в основном состоит из адипоцитов, она также содержит преадипоциты, иммунные клетки, фибробласты и сосудистые клетки. Количество и фенотип этих клеток изменяются в зависимости от локализации жировой ткани, а также различаются у людей с ожирением и худых [15]. БЖТ у худых обычно состоит из иммунных клеток, которые являются преимущественно регуляторными и иммуносупрессивными по своей природе, включая М2-подобные макрофаги жировой ткани (АТМ), регуляторные Т-клетки (Treg), Т-хелперы (Th) типа 2, инвариантные натуральные киллеры (iNKT) и эозинофилы. У худых людей АТМ являются преобладающими иммунными клетками, присутствующими в БЖТ, и составляют 5-15\% от общего количества клеток [16]. АТМ M2 равномерно распределены в жировой ткани и выполняют различные физиологические функции, в том числе способствуют удалению мертвых адипоцитов, ингибируют пролиферацию предшественников адипоцитов и секретируют противовоспалительные цитокины, такие как интерлейкины (IL-10, IL-4, IL-13 и IL-1Ra) [17, 18].

При ожирении происходит повышенное накопление липидов, что приводит к гипертрофии адипоцитов, гипоксии и повышенной гибели клеток. Дисфункция жировой ткани способствует изменению микроокружения, в котором увеличивается секреция провоспалительных цитокинов, включая фактор некроза опухоли альфа (TNF-a), интерлейкин-6 (IL-6), интерлейкин-8 (IL-8) и моноцитарный хемоаттрактантный протеин-1 (МСР-1), и других хемокинов, продуцируемых адипоцитами и иммунными клетками, что способствует усиленной миграции циркулирующих моноцитов и других клеток врожденного и адаптивного иммунитета в жировую ткань [19-21]. Повышенная инфильтрация моноцитами [16] и задержка в тканях макрофагов [22] способствуют значительному увеличению количества клеток моноцитарно-макрофагального ряда у пациентов с ожирением. Помимо увеличения количества макрофагов, провоспалительная среда в БЖТ у пациентов с ожирением способствует изменениям фенотипов АTM [18]. Первоначально считалось, что ожирение приводит к увеличению концентрации М1-провоспалительных макрофагов в БЖТ. Но недавно было обнаружено, что в БЖТ у пациентов с ожирением, кроме М1 макрофагов, присутствуют уникальные «метаболически активные макрофаги» с отчетливым провоспалительным профилем [23]. При ожирении в БЖТ увеличивается содержание тучных и дендритных клеток (DC), CD4+ Th1- и Th17-клеток и CD8+ цитотоксических Т-лимфоцитов [24-28]. Изменение баланса провоспалительных и противовоспалительных адипокинов и цитокинов представлено на рисунке 1.

Клинические данные свидетельствуют о том, что частота аутоиммунных заболеваний увеличивается параллельно с интенсивностью ожирения и метаболического синдрома [29]. В поддержку этой концепции, ожирение, вызванное диетой, усугубляет проявления аутоиммунных заболеваний, что было убедительно продемонстрировано на экспериментальных моделях животных, включая воспалительные заболевания кишечника [30], коллаген-индуцированный артрит [31], экспериментальный аутоиммунный энцефаломиелит (EAE, модель рассеянного склероза) $[32,33]$ и системную красную волчанку (СКВ) [34].

\section{ЭНДОТОКСИН (ЛИПОПОЛИСАХАРИД) ГРАМНЕГАТИВНЫХ БАКТЕРИЙ}

Эндотоксины представляют собой термостойкие липополисахариды (LPS), которые являются основным гликолипидным компонентом внешней мембраны грамотрицательных бактерий [35], составляющих приблизительно 70\% от общего количества бактерий в кишечнике [36]. 
Взаимодействие моноцитарно-макрофагальных клетоK с LPS в основном осуществляется через рецепторы mCD14 и TLR-4/MD-2 (толл-подобные рецепторы 4 типа с адаптерным белком - MD-2).

K гуморальным LPS-связывающим системам относятcя: LPS-связывающий белок (LBP), анти-LPS-антитела, растворимые CD14 (sCD14) рецепторы, С-реактивный белок (CRP), амилоид A, лизоцим, липопротеины высокой плотности (ЛПВП), липопротеины низкой плотности (LDL), белок теплового шока HSP 60, интерферон, альбумин, лактоферрин, аполипопротеины (АроB, АроА-І, АроЕ), фибронектин, гликопротеины (САР18, САР33), антитела к Re-гликолипиду (глубокая детерминанта R-кора), состоящие из липида А и кетодезоксиоктанта [37].

Липид А является наиболее важной частью LPS и основным центром иммуностимулирующей способности LPS, поскольку он специфически распознается комплекcoм TLR4/MD-2 [38, 39]. Наибольшей способностью к активации комплекса TLR4/MD-2 и последующему запуску провоспалительного ответа обладает гексаацилированный липид А [39-41]. Провоспалительная активность коррелирует со способом связывания липида А с комплексом TLR4/MD-2 [42]. В настоящее время имеются лишь ограниченные данные о нескольких формах LPS с антивоспалительным эффектом, способных конкурировать с токсичным LPS за связывание с TLR4/MD-2, предотвращая, таким образом, генерацию провоспалительного ответа [41]. К таким формам относится тетраацильный липид A, который свойствен определенным видам бактерий рода Bacteroides [41, 43, 44].

\section{ВОРОТА ДЛЯ ЭНДОТОКСИНА}

LPS могут перемещаться в систему кровообращения посредством прямой диффузии из-за кишечной парацеллюлярной проницаемости или в составе хиломикрон [45]. В дальнейшем LPS может транспортироваться в гепатоциты, связываясь с лПВП, лПНП или хиломикронами для последующей инактивации (деацилирования) и экскреции с желчью $[45,46]$ (рис. 2). Ряд состояний, таких как стресс, вирусные заболевания, дисбактериоз кишечника, погрешности в диете и антибиотикотерапия, могут увеличивать объем поступающего в кровоток LPS - индуцировать системное воспаление, что было постулировано М.Ю. Яковлевым еще в конце XX в. [47]. Согласно исследованию d'Hennezel и соавт., у лиц с ожирением дисбаланс кишечной микрофлоры приводит к увеличению поступления в системный кровоток LPS с гексаацильным липидом A [48]. Кроме этого, известно, что диета с высоким содержанием жиров увеличивает проницаемость кишечника с помощью различных механизмов: изменяет распределение и снижает экспрессию плотных контактов, индуцирует апоптоз эпителиальных клеток кишечника, прямо и косвенно стимулирует провоспалительные сигнальные каскады, увеличивая продукцию разрушающих эпителиальный слой цитокинов, уменьшая уровень барьерных цитокинов; отрицательно модулирует состав кишечной слизи и обогащает микрофлору кишечника видами, разрушающими слизистый барьер $[49,50]$.

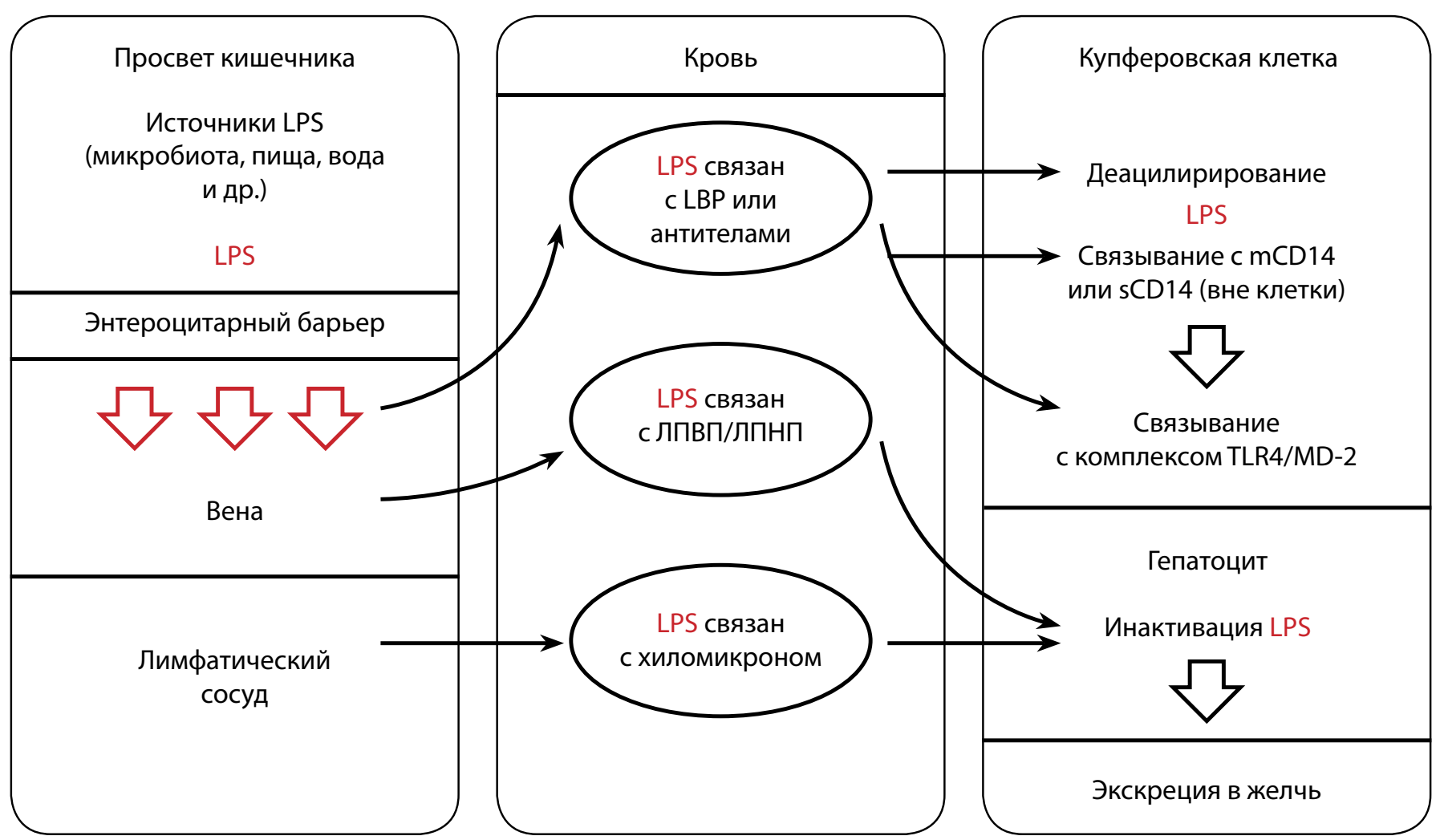

Рисунок 2. Основные пути поступления и метаболизма LPS.

LPS - липополисахарид; LBP - липополисахарид-связывающий белок; ЛПВП - липопротеины высокой плотности; ЛПНП липопротеины низкой плотности; mCD14 - сцепленный с мембраной CD14; sCD14 - растворимая форма CD14; TLR4/MD-2 — рецепторный комплекс, распознающий липополисахарид. 


\section{МЕТАБОЛИЧЕСКАЯ ЭНДОТОКСИНЕМИЯ}

Cani и соавт. описали так называемую «метаболическую эндотоксинемию» как состояние хронически повышенного уровня LPS в плазме крови на уровне в 10-50 раз ниже, чем при септических состояниях [51]. Метаболическая эндотоксинемия как наблюдалась у генетически страдающих ожирением мышей, потребляющих нормальный корм, так и индуцировалась у тощих мышей, потребляющих высококалорийную диету [51]. Повышение уровня эндотоксина, вызванное высококалорийной диетой, было связано с повышенным отложением жира, повышением активации провоспалительных каскадов, перекисного окисления и выработки резистентности к инсулину $[11,51]$. Эти результаты доказывают, что кишечный эндотоксин является важнейшим индуктором повышенной провоспалительной активности в экспериментальной модели ожирения у грызунов [11].

Роль эндотоксина как медиатора развития жировой ткани, системных и локальных воспалительных процессов и метаболических нарушений была подтверждена в эксперименте при введении низких доз LPS худым мышам, которые находились на стандартной диете [51]. Инъекция 300 мкг/кг/день LPS вызывала у худых мышей сходные нарушения, как и при ожирении, вызванном высококалорийной диетой. Кроме того, худые мыши, лишенные кластера дифференцировки CD14, были устойчивы к увеличению веса, вызванному диетой с высоким содержанием жиров, тканеспецифическому воспалению, отложению липидов в печени и резистентности к инсулину [51]. LPS может инициировать системное и локальное воспаление, а также приводить к продукции активных форм кислорода (ROS) при связывании с TLR4 и последующей активации NF-кB [52-54]. TLR4 широко экспрессируется на иммунных клетках, клетках печени, жировой ткани и в скелетных мышцах [55-57]. В совокупности эти ткани играют важную роль в регуляции гомеостаза глюкозы и липидов. Установлено, что провоспалительные цитокины и продуцирование ROS влияют на нормальный метаболизм в этих тканях [27-30]. Так, Cani и соавт. сообщили о повышенной выработке провоспалительных цитокинов (например, TNFa, IL-6, IL-1), усилении окислительного стресса (НАДФН-оксидаза, индуцируемая синтаза оксида азота) и увеличении маркеров инфильтрации макрофагов (CD86) в ткани печени у мышей с ожирением и метаболической эндотоксинемией [25].

В то время как существует большое количество зарубежных и отечественных работ по изучению эндотоксинемии на животных моделях, данных о взаимосвязи LPS и метаболических заболеваний у людей на данный момент значительно меньше.

LPS присутствует в низких концентрациях и у здоровых людей, но даже однократный прием пищи с высоким содержанием жиров уже может значительно увеличить уровни циркулирующего в крови эндотоксина $[58,59]$. В исследованиях последних лет сообщается о повышенных уровнях LPS и LBP у пациентов с метаболическим синдромом или СД2 [7, 60-62]. Так, Pussinen и соавт. проанализировали уровни LPS у пациентов с СД2 и сравнили их с контрольной группой, в которой около $20 \%$ пациентов имели метаболический синдром. Уровень эндотоксина был значительно повышен улиц с СД2 [7]. Парентеральное введение LPS провоцировало развитие инсулинорезистентности и системного воспаления [8], а интервенция с перееданием продолжительностью 8 нед была связана с повышением уровня эндотоксина в плазме крови, что подтверждает связь избыточного питания с эндотоксинемией и развитием инсулинорезистентности [9]. В недавнем исследовании Сох и соавт. использовали LPS, LBP, а также белок, связывающий жирные кислоты кишечника (iFABP), для расчета показателя риска кишечной проницаемости, который был повышен улиц с СД2 [63]. Также наличие у пациентов неалкогольной жировой болезни печени (НАЖБП) было связано с еще более высоким уровнем эндотоксина в крови [64].

В нашем предшествующем исследовании у пациентов, коморбидных по сезонному аллергическому риниту (САР), артериальной гипертензии (АГ) и ожирению выявлено повышение в периферической крови уровня рецепторов СРБ, LBP и sCD14, что свидетельствует о наличии системного хронического воспаления и участии провоспалительных LPS-связывающих механизмов в персистенции данного воспаления. Также было установлено наличие связи между концентрацией СРБ и LBP у пациентов с ожирением в период поллинации причинно-значимых аллергенов, что свидетельствует о наличии функциональной взаимосвязи обострения локального Т2-аллергического воспаления, системного воспаления и провоспалительного ответа ЛПС-связывающих систем при метаболической эндотоксинемии [65].

Высокий уровень циркулирующего эндотоксина вследствие увеличения кишечной проницаемости и нарушения микробиома, а также дисбаланс LPS-связывающих систем являются клинически значимыми факторами в развитии сердечно-метаболических заболеваний. Например, повышенная базовая концентрация эндотоксина в сыворотке натощак явилась предиктором кардиоваскулярных событий в течение 10 лет у лиц с ишемической болезнью сердца [65]. Кроме того, риск развития диабета увеличился у здоровых лиц в возрасте 25-75 лет с повышенным уровнем эндотоксина в сыворотке крови при последующем динамическом наблюдении на протяжении 10 лет [7]. В китайском когортном исследовании было доказано, что риск развития метаболического синдрома и большинства его компонентов (включая ожирение) повышен у людей среднего возраста и пожилых с повышенным уровнем LBP [66].

\section{ЗАКЛЮЧЕНИЕ}

В связи с увеличением доли населения, страдающего избыточным весом и ожирением, проблема гормональной и иммунной перестройки жировой ткани, а также влияния высококалорийных диет и ожирения на уровень эндотоксина в крови становится все более актуальной. Данные метаболические нарушения могут стать триггерами развития и прогрессирования целого спектра острых и хронических заболеваний, приводить в последующем к увеличению инвалидизации и смертности трудоспособного населения страны. Углубленное изучение способности ожирения и эндотоксинемии потенцировать взаимное провоспалительное действие может помочь как в понимании патогенеза основных сердечно-сосудистых, аутоиммунных, аллергических и инфекционных (в том числе вирусных) заболеваний, так и в разработке методов нефармакологической и медикаментозной коррекции данных состояний. 


\section{ДОПОЛНИТЕЛЬНАЯ ИНФОРМАЦИЯ}

Источники финансирования. Работа выполнена по инициативе авторов без привлечения финансирования.

Конфликт интересов. Авторы декларируют отсутствие явных и потенциальных конфликтов интересов, связанных с содержанием настоящей статьи.

Участие авторов. Белоглазов В.А. - концепция статьи, анализ публикаций, интерпретация результатов, внесение существенных правок с целью повышения научной ценности статьи; Яцков И.А. - анализ публикаций, интерпретация результатов, внесение существенных правок с целью повышения научной ценности статьи; Кумельский Е.Д. - сбор и систематизация данных, написание статьи; Половинкина В.В. - сбор и систематизация данных, написание статьи. Все авторы одобрили финальную версию статьи перед публикацией, выразили согласие нести ответственность за все аспекты работы, подразумевающую надлежащее изучение и решение вопросов, связанных с точностью или добросовестностью любой части работы.

\section{СПИСОК ЛИТЕРАТУРЫ | REFERENCES}

1. Flegal KM, Kruszon-Moran D, Carroll MD, et al. Trends in Obesity Among Adults in the United States, 2005 to 2014. JAMA. 2016;315(21):2284-2291. doi: https://doi.org/10.1001/jama.2016.6458

2. Afshin A, Forouzanfar MH, Reitsma MB, et al. Health Effects of Overweight and Obesity in 195 Countries over 25 Years. N Eng/ J Med. 2017;377(1):13-27. doi: https://doi.org/10.1056/NEJMoa1614362

3. Arner P. Differences in lipolysis between human subcutaneous and omental adipose tissues. Ann Med. 1995;27(4):435-438. doi: https://doi.org/10.3109/07853899709002451

4. Gregor MF, Hotamisligil GS. Inflammatory mechanisms in obesity. Annu Rev Immunol. 2011;29:415-445. doi: https://doi.org/10.1146/annurev-immunol-031210-101322

5. Dandona P, Aljada A, Bandyopadhyay A. Inflammation: The link between insulin resistance, obesity and diabetes. Trends in Immunology. 2004;25:4-7. doi: https://doi.org/10.1016/j.it.2003.10.013

6. Van Gaal LF, Mertens IL, Christophe E. Mechanisms linking obesity with cardiovascular disease. Nature. 2006; 444:875-880. doi: https://doi.org/10.1038/nature05487

7. Pussinen PJ, Havulinna AS, Lehto M, et al. Endotoxemia is associated with an increased risk of incident diabetes. Diabetes Care. 2011;34:392-397. doi: https://doi.org/10.2337/dc10-1676

8. Agwunobi AO, Reid C, Maycock P, et al. Insulin resistance and substrate utilization in human endotoxemia. The Journal of Clinical Endocrinology and Metabolism. 2000;85:3770-3778. doi: https://doi.org/10.1210/jcem.85.10.6914

9. Krogh-Madsen R, Plomgaard P, Akerstrom T, et al. Effect of short-term intralipid infusion on the immuneresponse during low-dose endotoxemia in humans. The Journal of Clinical Endocrinology and Metabolism. 2008;294:371-379. doi: https://doi.org/10.1152/ajpendo.00507.2007

10. Яковлев М.Ю. Системная эндотоксинемия. Гомеостаз и общая патология. - М.: Наука; 2021. [Yakovlev MYu. Sistemnaya endotoksinemiya. Gomeostaz I obshchaya patologiya. Moscow: Nauka; 2021. (In Russ.)].

11. Mongraw-Chaffin M, Hairston KG, Hanley AJG, et al. Association of Visceral Adipose Tissue and Insulin Resistance with Incident Metabolic Syndrome Independent of Obesity Status: The IRAS Family Study. Obesity. 2021;29(7):1195-1202. doi: https://doi.org/10.1002/oby.23177

12. Kissebah AH, Vydelingum N, Murray R, et al. Relation of body fat distribution to metabolic complications of obesity. J Clin Endocrinol Metab. 1982;54(2):254-260. doi: https://doi.org/10.1210/jcem-54-2-254

13. Lemieux I, Després J-P. Metabolic Syndrome: Past, Present and Future. Nutrients. 2020;12(11):3501. doi: https://doi.org/10.3390/nu12113501

14. Gastaldelli A, Miyazaki Y, Pettiti M, et al. Metabolic effects of visceral fat accumulation in type 2 diabetes. J Clin Endocrinol Metab. 2002;87(11):5098-5103. doi: https://doi.org/10.1210/jc.2002-020696

15. Ouchi N, Parker JL, Lugus JJ, Walsh K. Adipokines in inflammation and metabolic disease. Nat Rev Immunol. 2011;11 (2):85-97. doi: https://doi.org/10.1038/nri2921

16. Kunz HE, Hart CR, Gries KJ, et al. Adipose tissue macrophage populations and inflammation are associated with systemic inflammation and insulin resistance in obesity. Am J Physiol Metab. 2021;321(1):E105-E121 doi: https://doi.org/10.1152/ajpendo.00070.2021
17. Nawaz A, Aminuddin A, Kado T, et al. CD206+ M2-like macrophages regulate systemic glucose metabolism by inhibiting proliferation of adipocyte progenitors. Nat Commun. 2017;8(1):286. doi: https://doi.org/10.1038/s41467-017-00231-1

18. Lumeng CN, Bodzin JL, Saltiel AR. Obesity induces a phenotypic switch in adipose tissue macrophage polarization. J Clin Invest. 2007;117(1):175-184. doi: https://doi.org/10.1172/JCI29881

19. Nara N, Nakayama Y, Okamoto S, et al. Disruption of CXC motif chemokine ligand-14 in mice ameliorates obesity-induced insulin resistance. J Biol Chem. 2007;282(42):30794-30803. doi: https://doi.org/10.1074/jbc.M700412200

20. Kochumon S, Al Madhoun A, Al-Rashed F, et al. Elevated adipose tissue associated IL-2 expression in obesity correlates with metabolic inflammation and insulin resistance. Sci Rep. 2020;10(1):16364. doi: https://doi.org/10.1038/s41598-020-73347-y

21. Duffaut C, Zakaroff-Girard A, Bourlier V, et al. Interplay between human adipocytes and T lymphocytes in obesity: CCL20 as an adipochemokine and T lymphocytes as lipogenic modulators. Arterioscler Thromb Vasc Biol. 2009;29(10):1608-1614. doi: https://doi.org/10.1161/ATVBAHA.109.192583

22. Ramkhelawon B, Hennessy EJ, Ménager M, et al. Netrin-1 promotes adipose tissue macrophage retention and insulin resistance in obesity. Nat Med. 2014;20(4):377-384. doi: https://doi.org/10.1038/nm.3467

23. Kratz M, Coats BR, Hisert KB, et al. Metabolic dysfunction drives a mechanistically distinct proinflammatory phenotype in adipose tissue macrophages. Cell Metab. 2014;20(4):614-625. doi: https://doi.org/10.1016/j.cmet.2014.08.010

24. Bertola A, Ciucci T, Rousseau D, et al. Identification of adipose tissue dendritic cells correlated with obesity-associated insulin-resistance and inducing Th17 responses in mice and patients. Diabetes. 2012;61(9):2238-2247. doi: https://doi.org/10.2337/db11-1274

25. Stefanovic-Racic M, Yang X, Turner MS, et al. Dendritic cells promote macrophage infiltration and comprise a substantial proportion of obesity-associated increases in CD11c+ cells in adipose tissue and liver. Diabetes. 2012;61(9):2330-2339. doi: https://doi.org/10.2337/db11-1523

26. Liu J, Divoux A, Sun J, et al. Genetic deficiency and pharmacological stabilization of mast cells reduce diet-induced obesity and diabetes in mice. Nat Med. 2009;15(8):940-945. doi: https://doi.org/10.1038/nm.1994

27. Nishimura S, Manabe I, Nagasaki M, et al. CD8+ effector T cells contribute to macrophage recruitment and adipose tissue inflammation in obesity. Nat Med. 2009;15(8):914-920. doi: https://doi.org/10.1038/nm.1964

28. Hotamisligil GS, Shargill NS, Spiegelman BM. Adipose expression of tumor necrosis factor-alpha: direct role in obesitylinked insulin resistance. Science. 1993;259(5091):87-91. doi: https://doi.org/10.1126/science.7678183

29. Manzel A, Muller DN, Hafler DA, et al. Role of «Western diet» in inflammatory autoimmune diseases. Curr Allergy Asthma Rep. 2014;14(1):404. doi: https://doi.org/10.1007/s11882-013-0404-6

30. Paik J, Fierce $Y$, Treuting PM, et al. High-fat diet-induced obesity exacerbates inflammatory bowel disease in genetically susceptible Mdr1a-/- male mice. J Nutr. 2013;143(8):1240-1247. doi: https://doi.org/10.3945/jn.113.174615

31. Chehimi M, Vidal H, Eljaafari A. Pathogenic Role of IL-17-Producing Immune Cells in Obesity, and Related Inflammatory Diseases. J Clin Med. 2017;6(7):68. doi: https://doi.org/10.3390/jcm6070068

32. Winer $\mathrm{S}$, Paltser $\mathrm{G}$, Chan Y, et al. Obesity predisposes to Th17 bias. Eur J Immunol. 2009;39(9):2629-2635. doi: https://doi.org/10.1002/eji.200838893 
33. Timmermans S, Bogie JF, Vanmierlo T, et al. High fat diet exacerbates neuroinflammation in an animal model of multiple sclerosis by activation of the Renin Angiotensin system. J Neuroimmune Pharmacol. 2014;9(2):209-217. doi: https://doi.org/10.1007/s11481-013-9502-4

34. Hanna Kazazian N, Wang Y, Roussel-Queval A, et al. Lupus Autoimmunity and Metabolic Parameters Are Exacerbated Upon High Fat Diet-Induced Obesity Due to TLR7 Signaling. Front Immunol. 2019;10:2015. doi: https://doi.org/10.3389/fimmu.2019.02015

35. Adamik B, Smiechowicz J, Kübler A. The importance of early detection of endotoxemia. Innate Immunity. 2016;22(7):503-509. doi: https://doi.org/10.1177/1753425916660177

36. Raetz CR, Whitfield C. Lipopolysaccharide endotoxins. Annual Review of Biochemistry. 2002;71:635-700. doi: https://doi.org/10.1146/annurev.biochem.71.110601.135414

37. Gordienko Al, Beloglazov VA, Kubyshkin AV, et al. Humoral Anti-Endotoxin Immunity Imbalance as a Probable Factor in the Pathogenesis of Autoimmune Diseases. Hum Physiol. 2019:45:337-341. doi: https://doi.org/10.1134/S036211971903006X

38. Di Lorenzo F, Kubik $Ł$, Oblak A, et al. Activation of Human Toll-like Receptor 4 (TLR4) Myeloid Differentiation Factor 2 (MD-2) by Hypoacylated Lipopolysaccharide from a Clinical Isolate of Burkholderiacenocepacia. Journal of Biological Chemistry. 2015;290(35):21305-21319. doi: https://doi.org/10.1074/jbc.m115.649087

39. Molinaro A, Holst O, Di Lorenzo F, et al. Chemistry of Lipid A: At the Heart of Innate Immunity. Chem - A Eur J. 2015;21 (2):500-519. doi: https://doi.org/10.1002/chem.201403923

40. Munford RS. Sensing Gram-Negative Bacterial Lipopolysaccharides: a Human Disease Determinant? Infection and Immunity. 2008;76:454-465. doi: https://doi.org/10.1128/iai.00939-07

41. Di Lorenzo F, Palmigiano A, Al Bitar-Nehme S, et al. The Lipid A from Rhodopseudomonaspalustris Strain BisA53 LPS Possesses a Unique Structure and Low Immunostimulant Properties. Chemistry. 2017;23(15):3637-3647. doi: https://doi.org/10.1002/chem.201604379

42. Park BS, Song DH, Kim HM, et al.

The structural basis of lipopolysaccharide recognition by the TLR4-MD-2 complex. Nature. 2009;458:1191-1195. doi: https://doi.org/10.1038/nature07830

43. Lembo-Fazio L, Billod JM, Di Lorenzo F, et al. Bradyrhizobium Lipid A: Immunological Properties and Molecular Basis of Its Binding to the Myeloid Differentiation Protein-2/Toll-Like Receptor 4 Complex. Frontiers in Immunology. 2018;9:1888. doi: https://doi.org/10.3389/fimmu.2018.01888

44. Pallach M, Di Lorenzo F, Facchini FA, et al. Structure and inflammatory activity of the LPS isolated from Acetobacterpasteurianus CIP103108. International Journal of Biological Macromolecules. 2018;1 19:1027-1035. doi: https://doi.org/10.1016/j.jijbiomac.2018.08.035

45. Moreira AP, Texeira TF, Ferreira AB, et al. Influence of a high-fat diet on gut microbiota, intestinal permeability and metabolic endotoxaemia. Br J Nutr. 2012;108(5):801-809. doi: https://doi.org/10.1017/S0007114512001213

46. Покусаева Д.П., Аниховская И.А., Коробкова Л.А и др. Прогностическая значимость показателей системной эндотоксинемии в атерогенезе // Физиология человека. 2019. - T. 45. - №5. - C. 543-551. [Pokusaeva DP, Anikhovskaya IA, Korobkova $L A$, et al. Prognostic significance of indicators of systemic endotoxinemia in atherogenesis. Fiziol Cheloveka. 2019;45(5):543-551. (In Russ.)]. doi: https://doi.org/10.1134/S0131164619050138

47. Яковлев М.Ю. Роль кишечной микрофлоры и недостаточность барьерной функции печени в развитии эндотоксинемии и воспаления // Казанский медииинский журнал. - 1988. T. 69. — №5. - C. 353-358. [Yakovlev MY. The role of intestinal microflora and insufficiency of the liver barrier function in the development of endotoxinemia and inflammation. Kazan Medical Journal. 1988;69(5):353-358. (In Russ.)].

48. d'Hennezel E, Abubucker S, Murphy LO, Cullen TW. Total Lipopolysaccharide from the Human Gut Microbiome Silences Toll-Like Receptor Signaling. mSystems. 2017;2(6). doi: https://doi.org/10.1128/mSystems.00046-17

49. Popkin BM, Du S, Green WD, et al. Individuals with obesity and COVID-19: A global perspective on the epidemiology and biological relationships. Obes Rev. 2020;21(11):e13128. doi: https://doi.org/10.1111/obr.13128
50. Nagpal R, Newman TM, Wang S, et al. Obesity-Linked Gut Microbiome Dysbiosis Associated with Derangements in Gut Permeability and Intestinal Cellular Homeostasis Independent of Diet. J Diabetes Res. 2018;2018:1-9. doi: https://doi.org/10.1155/2018/3462092

51. Cani PD, Amar J, Iglesias MA, et al. Metabolic endotoxemia initiates obesity and insulin resistance. Diabetes. 2007;56:1761-1772. doi: https://doi.org/10.2337/db06-1491

52. Ciesielska A, Matyjek M, Kwiatkowska K. TLR4 and CD14 trafficking and its influence on LPS-induced proinflammatory signaling. Cell Mol Life Sci. 2021;78(4):1233-1261. doi: https://doi.org/10.1007/s00018-020-03656-y

53. Karpova T, de Oliveira AA, Naas H, et al. Blockade of Toll-like receptor 4 (TLR4) reduces oxidative stress and restores phosphoERK1/2 levels in Leydig cells exposed to high glucose. Life Sciences. 2020;245:117365. doi: https://doi.org/10.1016/j.lfs.2020.117365

54. Li Y, Deng S-L, Lian Z-X, Yu K. Roles of Toll-Like Receptors in Nitroxidative Stress in Mammals. Cells. 2019; 8(6):576. doi: https://doi.org/10.3390/cells8060576

55. Frost RA, Nystrom GJ, Lang CH. Lipopolysaccharide regulates proinflammatory cytokine expression in mouse myoblasts and skeletal muscle. Am J Physiol Integr Comp Physiol. 2002;283(3):R698-R709. doi: https://doi.org/10.1152/ajpregu.00039.2002

56. Kong $X$, Yang $Y$, Ren $L$, et al. Activation of autophagy attenuates EtOH-LPS-induced hepatic steatosis and injury through MD2 associated TLR4 signaling. Sci Rep. 2017;7(1):9292. doi: https://doi.org/10.1038/s41598-017-09045-z

57. Song MJ, Kim KH, Yoon JM, Kim JB. Activation of toll-like receptor 4 is associated with insulin resistance in adipocytes. Biochemical and Biophysical Research Communications. 2006;346:739-745. doi: https://doi.org/10.1016/j.bbrc.2006.05.170

58. Okorokov PL, Anychovskaya IA, Yakovleva MM, et al. Nutritional factors of inflammation induction or lipid mechanism of endotoxin transport. Hum Physiol. 2012;38(6):649-655. doi: https://doi.org/10.1134/S0362119712060102

59. 59. Harte AL, Varma MC, Tripathi G, et al. High fat intake leads to acute postprandial exposure to circulating endotoxin in type 2 diabetic subjects. Diabetes Care. 2012;35:375-382. doi: https://doi.org/10.2337/dc11-1593

60. Lassenius MI, Pietilainen KH, Kaartinen $\mathrm{K}$, et al. Bacterial endotoxin activity in human serum is associated with dyslipidemia, insulin resistance, obesity, and chronic inflammation. Diabetes Care. 2011;34:1809-1815. doi: https://doi.org/10.2337/dc10-2197

61. Monte SV, Caruana JA, Ghanim H, et al. Reduction in endotoxemia, oxidative and inflammatory stress, and insulin resistance after Roux-en- $Y$ gastric bypass surgery in patients with morbid obesity and type 2 diabetes mellitus. Surgery. 2012;151:587-593. doi: https://doi.org/10.1016/j.surg.2011.09.038

62. Cox AJ, Zhang P, Bowden DW, et al. Increased intestinal permeability as a risk factor for type 2 diabetes. Diabetes and Metabolism. 2017:43:163-166. doi: https://doi.org/10.1016/j.diabet.2016.09.004

63. Harte AL, da Silva NF, Creely SJ, et al. Elevated endotoxin levels in non-alcoholic fatty liver disease. Journal of Inflammation (London England). 2010;7:15. doi: https://doi.org/10.1186/1476-9255-7-15

64. Kallio KAE, Hätönen KA, Lehto $M$, et al. Endotoxemia, nutrition, and cardiometabolic disorders. Acta Diabetol. 2015;52(2):395-404. doi: https://doi.org/10.1007/s00592-014-0662-3

65. Усаченко Ю.В., Белоглазов В.А., Гордиенко А.И. Системное воспаление, уровень липополисахарид-связывающего белка и растворимых SCD14 рецепторов при коморбидности сезонного аллергического ринита, эссенциальной артериальной гипертензии и ожирения // Патогенез. 2020. - T. 18. - №3. - C. 61-67. [Usachenko JV, Beloglazov VA, Gordienko AI. Systemic inflammation, the level of lipopolysaccharide-binding protein and soluble sCD14 receptors in the comorbidity of seasonal allergic rhinitis, essential arterial hypertension and obesity. Patogenez. 2020;18(3):61-67. (In Russ.)]. doi: https://doi.org/10.25557/2310-0435.2020.03.61-67

66. Liu X, Lu L, Yao P, et al. Lipopolysaccharide binding protein, obesity status and incidence of metabolic syndrome: A prospective study among middleaged and older chinese. Diabetologia. 2014;57:1834-1841. doi: https://doi.org/10.1007/s00125-014-3288-7 


\section{ИНФОРМАЦИЯ ОБ АВТОРАХ [AUTHORS INFO]:}

*Яцков Игорь Анатольевич [Igor A. Yatskov, MD]; адрес: Россия, 295491, Симферополь, ул. Мальченко, д. 7 [address: 7 Malchenko street, 295491 Simferopol, Russia]; ORCID: https://orcid.org/0000-0002-5486-7262; Scopus Author ID: 57218873902; eLibrary SPIN: 2395-5710; e-mail: egermd@yandex.ru

Белоглазов Владимир Алексеевич, д.М.н., профессор [Vladimir A. Beloglazov, MD, PhD, Professor]; ORCID: https://orcid.org/0000-0001-9640-754X; Scopus Author ID: 7007129056; eLibrary SPIN: 7455-2188; e-mail: biloglazov@mail.ru

Кумельский Евгений Дмитриевич, аспирант [Evgeny D. Kumelsky, postgraduate student];

ORCID: https://orcid.org/0000-0001-5090-4516; eLibrary SPIN: 7455-2188; e-mail: ekum.rk@yandex.ru

Половинкина Валерия Владимировна, студент [Valeria V. Polovinkina, student];

ORCID: https://orcid.org/0000-0002-3567-6532; e-mail: wwaa.po@gmail.com

*Автор, ответственный за переписку / Corresponding author.

\section{ЦИТИРОВАТЬ:}

Белоглазов В.А., Яцков И.А., Кумельский Е.Д., Половинкина В.В. Метаболическая эндотоксинемия: возможные причины и последствия // Ожирение и метаболизм. - 2021. — Т. 18. — №3. - С. 320-326. doi: https://doi.org/10.14341/omet12750

\section{TO CITE THIS ARTICLE:}

Beloglazov VA, Yatskov IA, Kumelsky ED, Polovinkina VV. Metabolic endotoxemia: possible causes and consequences. Obesity and metabolism. 2021;18(3):320-326. doi: https://doi.org/10.14341/omet12750 